\title{
HOW ENVIRONMENTAL VARIABLES CAN DETERMINE THE CHIR PINE (PINUS ROXBURGHII SARG.) DISTRIBUTION IN SWAT HINDUKUSH RANGE OF PAKISTAN: CURRENT AND FUTURE PROSPECTIVE OF THE SPECIES
}

\author{
KHAN, N. $.^{*}-$ ALI, $\mathrm{K}^{2}{ }^{2}-\mathrm{SAEED}, \mathrm{S} .{ }^{3}$ \\ ${ }^{1}$ Department of Botany, University of Malakand, Chakdara Dir Lower 18800, Khyber \\ Pakhtunkhwa, Pakistan \\ ${ }^{2}$ School of General Education, College of the North Atlantic Qatar, P.O. Box 24449, Doha, \\ Qatar \\ ${ }^{3}$ Department of Botany, University of Balochistan, Quetta, Pakistan \\ *Corresponding author \\ e-mail: nasrullah.uom@gmail.com \\ (Received $1^{\text {st }}$ Jan 2021; accepted $14^{\text {th }}$ May 2021)
}

\begin{abstract}
Distribution patterns of plant species and their relationships with physiographic, soil and climatic variables were investigated in the subtropical pine forests across the natural limits in the Swat, Hindukush range of Pakistan. A vegetation survey identified 9 tree species belonging to 8 families and 8 genera, which were classified into 3 distinct vegetation communities with an average density ranging from 512-1231 individuals ha ${ }^{-1}$ and basal areas of 31.6-36 $\mathrm{m}^{2} \mathrm{ha}^{-1}$. Total density and basal area values for tree species located at higher elevations were lower than those in the middle and low elevation communities for all the species. We found that $P$. roxburghii had unimodal size distributions, suggesting that these populations are not at equilibrium and are changing over time. CCA-Ordination with the associated Monte Carlo permutation test was employed to explore the patterns of variation in vegetation distribution and identified elevation and soil organic matter as the most influential variables responsible for the changes in species composition. The MaxEnt predictive modeling results clearly indicate a significant difference in the present predicated inter-site floristic composition and distribution of the species, suggesting an overall restriction to the south, whereas, the future distribution model suggest a shift towards the neighbouring districts in the west. This study identified few significantly important environmental variables linked with $P$. roxburghii associations and their distribution across the study area. We recommend additional research that includes multiple sampling from varied locations and other abiotic and biotic variables throughout Pakistan and neighbouring countries for better understanding of the species niche modeling.
\end{abstract}

Keywords: species distribution modeling, environmental correlates, Hindukush range, climate change, conservation and management

\section{Introduction}

Disentangling of the principal mechanisms responsible for structuring plant communities has been a central research dilemma in community ecology (McCune and Grace, 2002; Condit et al., 2011). Several factors such as biogeochemical variations and edaphic, topographic, soil, and climatic variables allow for a suite of potential limiting factors and have varied effects on the vegetation structure and function at both local and regional scales (Song et al., 2004; Miehe et al., 2009). However, the effects of such factors on vegetation distribution were not examined until the advent of multivariate statistical techniques and bioclimatic models for the forest tree species in the northern mountainous ranges of Pakistan (Khan et al., 2011). The prominent role of environmental 
and climatic factors in determining distribution by the Pine, coniferous and broadleaved woodlands in northern Pakistan is still not properly documented except for the scanty work done by Siddiqui et al. (2010), Ahmed et al. (2011), Khan et al. (2013, 2014).

Mountain ecosystems are often regarded as being particularly sensitive to environmental factors (Shaheen et al., 2011) and climate change (Trevidi et al., 2008). However, this has rarely been investigated at the scale of individual mountain ranges or parts of ranges using vegetation environmental and climate relationships in northern Pakistan. The adverse effects of climate change on vegetation has been reported by several workers in different countries including Pakistan (e.g. Miehe et al., 2009) as this phenomenon has been supported by the climate data monitors and reported $1.5-4.5^{\circ} \mathrm{C}$ increase in annual temperature using climatic models (Song et al., 2004). The IPCC (2013) has reported that increase in anthropogenic activities and industries will warm the climate and could lead to an increase in global average surface temperature of 1.1$6.4^{\circ} \mathrm{C}$ by 2100 century. Hence, it is predicted that climate change will have profound biological effects, such as shifts in range of species distribution that are expected to be northwards (Barry et al., 1995).

Under the climate change scenario, Pakistan is recognized as one of the most vulnerable countries in South-Asia due to which several tree species are expected to vanish, particularly from the northern mountain ranges (Ali et al., 2014). In these mountains, the vegetation in Swat Hindukush range is comparatively undisturbed, which provides an ideal habitat for research on tree species distribution and its response to environmental variables and climate change. However, the drastic change in the forest composition and structure driven by climatic, environmental and human disturbances has recently been shown to be complex in nature (Ali et al., 2014). In addition, large scale fragmentation in these forest patches has resulted in increased number of threatened species and hence they are at a great risk of losing plant diversity (Ahmed et al., 2011). Numerous shifts in the distribution patterns and abundance of species have been recorded (Thomas et al., 2004) due to climatic variables such as temperature and precipitation that have significant effect on the distribution and population density of species. It is suggested that if the shift in the distribution of species does not occur towards suitable environmental regions, such species will face a serious risk of extinction (Thomas, 2011).

Some environmental regions are very prone to climate changes, i.e. the Mediterranean and Asian regions where droughts and unpredicted precipitation patterns will bring many changes. Species of many mountainous ecosystems will show different plastic and evolutionary strategies to cope climate change and most of them should move upward in altitude (Song et al., 2004). Despite the presence of such climatic and anthropogenic disturbances, the remaining primary forests of Swat Hindukush range of Pakistan lack studies that explain vegetation-environment and climatic relationships in a quantitative manner. Some studies (e.g. Ahmed et al., 2006, 2011; Siddiqui et al., 2009) used semi-formal non-numerical approaches with insufficient environmental factors that did not expose the underlying group structure or the overriding factors responsible for the distribution of these forests. Such scanty information is not productive in implementing conservation strategies and the provision of baseline for planning and assessment of the success of restoration activities (Sarker et al., 2014). Therefore, a more thorough system is required to predict the present-day species distribution representing processes that are assumed to control species range limits (Song et al., 2004). The present study was conducted in the large-scale $P$. roxburghii natural forests 
in Swat Hindukush range of Pakistan. These forests are distributed on both sides of river Swat and in the inner valleys, classified under the subtropical dry temperate forests of the country (Champion et al., 1965) and typically occurring in the Sino-Japanese phytogeographical region of the world (Sher et al., 2014). Although, P. roxburghii is commercially and ecologically important and has high conservation value, but so far remains little explored by foresters and biologists (Khan et al., 2014).

In the present study, an attempt was made to explore $P$. roxburghii associations and their future distribution with environmental and climatic variables using advanced multivariate statistical methods and species distribution models (SDMs). Among the SDMs, MaxEnt model reliably predicts suitable habitat using presence records and pseudo-absence points (Phillips et al.; 2006; Elith et al., 2006) and have been widely used for the identification of suitable habitats, potential distribution range, and plant's future distribution changes (e.g., Ashraf et al., 2016; Abdelaal et al., 2019; Li et al., 2019; Kamyo and Asanok, 2020; Khan et al., 2020). Using both these techniques our specific research objectives were to examine (i) whether the occurrence of $P$. roxburghii is restricted to certain compositional and environmental circumstances (ii) whether $P$. roxburghii is regenerating in various community types linked with certain topographic, edaphic and climatic variables by analyzing its stand structures (iii) that density and recruitment of $P$. roxburghii in the forests can vary the structural characteristics of the stand, which may reflect an environmental gradient from various sites strongly dominated by $P$. roxburghii to those rich in broadleaved species and (iv) to simulate and compare the possible present and potential future distribution of $P$. roxburghii associations in Swat Hindukush range of Pakistan to assist its conservation and management.

\section{Materials and methods}

\section{Study area}

The Swat valley is part of the subtropical dry temperate areas in Hindukush range of northern Pakistan, located at $34^{\circ} 34^{\prime}$ to $35^{\circ} 55^{\prime} \mathrm{N}$ and $72^{\circ} 08^{\prime}$ to $72^{\circ} 50^{\prime} \mathrm{E}$ (Shinwari et al., 2003). The total area of the district is $5337 \mathrm{~km}^{2}$ with long stretches of pines, and it is generally considered as a hub to biodiversity due to its unique hills and climate (Ali et al., 2014). Geographically, the area shares borders with Chitral, Indus Kohistan, Shangla, Bunir and District Dir (Fig. 1). The area has a Mediterranean climate comprising two phytoclimatic subtypes: dry and moist (Champion et al., 1965). The Swat meteorological station data revealed that the average annual temperature is $19{ }^{\circ} \mathrm{C}$ and annual precipitation averages $897 \mathrm{~mm}$. Mean relative humidity remains high from January to March $(75 \%)$ and dips below $40 \%$ from May to June. The most abundant substrate consists of marble sandstones, which form soils of the sandy type only, and are accompanied by clays, marls and limestone in Vertisols (Ali et al., 2014). P. roxburghii stands constitute the most extensive plant formation in the area between altitudinal ranges from $700 \mathrm{~m}$ to $1800 \mathrm{~m}$ above sea level. $P$. roxburghii occurs either in pure stands or mixed with other species (Appendix 1) in the shady zones and the valley bottoms, as well as interspersed with Olea ferruginea and Quercus baloot in drier transition zones.

\section{Field methods}

After general reconnaissance of the Swat District, 25 sites were selected for sampling that approximately covered the entire range of $P$. roxburghii distribution in its natural 
zones of occurrence. The field sampling was conducted during July 2017 to March 2018. Prior to field data collection, stand locations were selected systematically using Arc GIS v. 9. Coordinate pairs and other geophysical characteristics were downloaded as waypoints into GPS receivers so that the forest stands could be located in the field. In addition, collection of geo-referenced data about the stands was ensured robust with RedHen DX-GPS system and Nikon D300 camera to gather and save the background information with pictures as metadata. Over 2,000 photographs of forest communities were obtained and metadata was extracted with the help of BR's EXIF extractor, a freeware available online (http://www.br-softwaare.com/extracter.hotml).

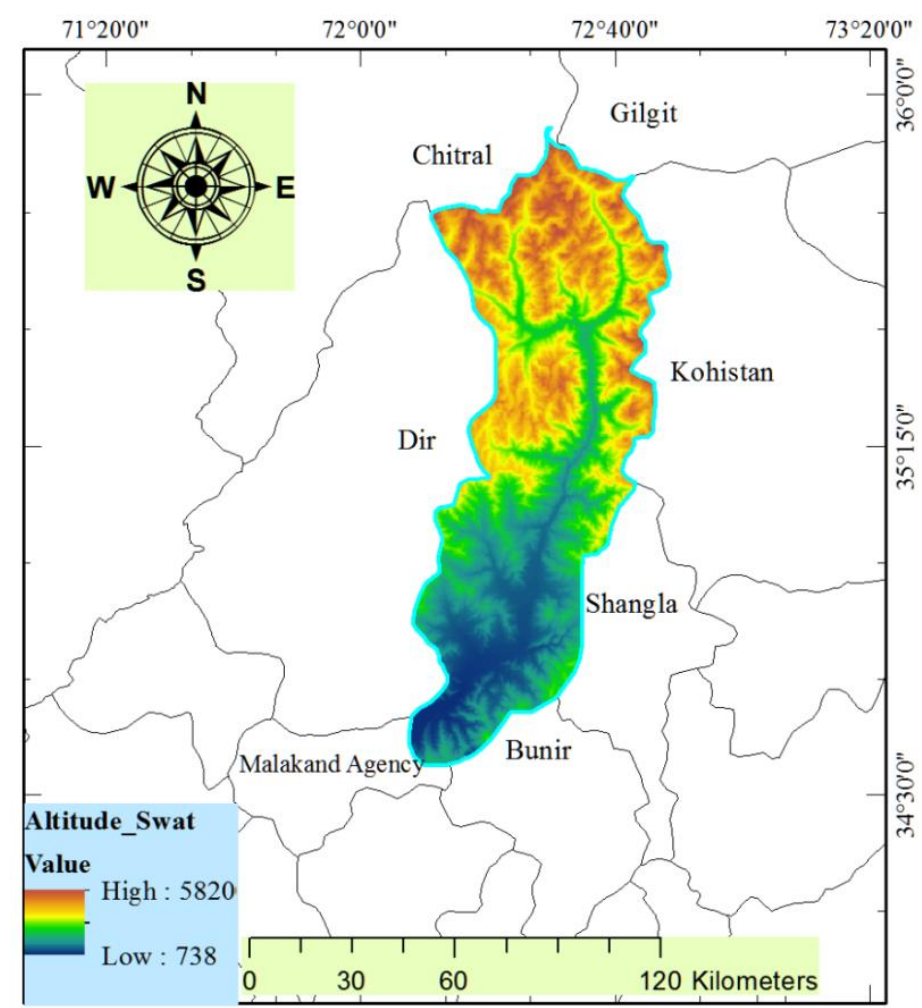

Figure 1. Map showing altitudinal topographical variations in Swat District Hindukush mountain range of Pakistan

At each forest stand, 30 quadrates of $10 \mathrm{~m} \times 10 \mathrm{~m}$ in size along a 200 meter straight transect in a suitable direction in both disturbed and undisturbed forests were phytosociologically analyzed (Uprety et al., 2014). All constituent trees of $\geq 10 \mathrm{~cm}$ diameter at breast height (DBH) were counted and $\mathrm{DBH}$ (above $1.37 \mathrm{~m}$ height) was measured with forestry tape to quantify species composition and structural characteristics. In addition, dead trees were identified and their density was obtained to quantify structural feature and disturbance history of the forest. For advance growth, the regeneration layer, i.e. sapling $(\leq 10 \mathrm{~cm})$ and seedling $(\leq 5 \mathrm{~cm})$ of $P$. roxburghii and associated tree species, were systematically sampled by laying down $5 \mathrm{~m} \times 5 \mathrm{~m}$ quadrates in the entire stands. We extracted two cores radii from living trees of $P$. roxburghii at breast height parallel to the slope contour in the opposite direction using Swedish increment borers (Appendix 1) to document age and radial growth. At least 2 cores from 30 randomly chosen individual trees were obtained with an attempt to 
achieve the pith of tree. Samples were placed with 2 end sealed plastic straws for safety with relevant information, i.e. DBH, site name and tree number. Six saplings were harvested from three different forests at low, middle, and high altitudinal zones at ground level to help determine the mean age at coring height following the method of Rigg et al. (1998). For each forest stand, soil samples from two pits (1 kg/pit at two different plots) were extracted at a depth of $30 \mathrm{~cm}$ using a bucket auger, and a pooled sample of $500 \mathrm{~g}$ was analysed in the Swat Agriculture Research Centre (SARC).

\section{Quantitative and laboratory methods}

Soil samples were air-dried, sieved through a 2-mm sieve, and analysed for texture (hydrometer method), $\mathrm{pH}$ (1:5 mixed soil-water solution using a digital $\mathrm{pH}$ meter model AS218), and total organic matter following the Springers-Klee method (Springer and Klee, 1954). The Kjeldahl method was used to determine total nitrogen (Bremner and Mulvaney 1982), available phosphorus was estimated following Olsen (1954), and exchangeable potassium by ammonium ions exchange using a galvanometer. Phytosociological attributes i.e. relative frequency; relative density, relative basal area, and importance value index (IVI) were calculated (Curtis and Mclntosh, 1950) for the overstory and understory species. Absolute values of density/ha and basal area $\mathrm{m}^{2} / \mathrm{ha}$ were obtained for tree and understory strata. The IVI values for tree species and environmental variables were subjected to PC-ORD v. 5.10 for objective classification and ordination of the forests. From various classification methods, hierarchical polythetic agglomerative cluster analysis was used and stands were merged (clustered) into groups with the results being displayed as a dendrogram (McCune and Grace, 2002). The quantitative Sorensen (Bray-Curtis) an effective distance measure for ecological community analysis (McCune and Grace, 2002) and flexible beta as a linkage method $(\beta=-0.25)$ was applied (Lance and Williams, 1967) which is compatible with Sorensen distance and is space-conserving (Legendre and Legendre, 1998). We used the Kruskal-Wallis test an alternative of one-way ANOVA to compare the environmental variables among different communities.

Detrended correspondence analysis (DCA), an indirect gradient analysis, was applied to identify the major gradient that influence species distribution. Preliminary analyses were made by applying the default option of DCA (Hill and Gauch, 1980) to check the magnitude of change in species composition along the first axis (i.e. gradient length in standard deviation (SD) units). In the present study, DCA estimated the compositional gradient in the vegetation data to be larger than 4.0 SD units for the first axis; thus, canonical correspondence analysis (CCA) was the appropriate ordination method to perform direct gradient analysis (terBraak, 1986). CCA was performed using 12 environmental variables after the exclusion of calcium, magnesium and electric conductivity as these variables were highly correlated and thus showed no significant differences among community types. All the default settings were used for CCA, and a Monte Carlo permutation test (499 permutations) was used to test for significance of the eigen-values of the first conical axis. Intra-set correlations from the CCAs were used to assess the importance of environmental variables.

All the tree species were grouped into different diameter classes of 10-20, and 21-30, and so on in each community type and Weibull function was fitted following Ryniker et al. (2006). Cores obtained were mounted, sanded, and polished with sandpapers of progressively finer grit until a fine surface was obtained as detailed in Stroke and Smiley (1996). These samples were measured to a precision of $0.001 \mathrm{~mm}$ under a 
stereo-microscope attached with a Velmex Measuring System (V. 10.6). The age of the trees was determined by counting the number of rings from the outermost ring to the pith. When the pith was not obtained in the core samples, we estimated the age of the ring closest to pith according to its shape of curvature (Xing et al., 2012). It is worth noting that the age of these trees thus obtained is the age of the stem at breast height, because the age does not include the time that the tree grow from the ground to the sampling height. Therefore, following Ogden and Ahmed (1989), rings obtained from sapling were added to the trees age in order to obtain total age of the trees. Linear regression was used to calibrate the relationship between age and size of the trees. For climate change modeling, the metadata obtained were transformed into CSV commadelimited text file format that can be used with the Maximum Entropy (MaxEnt) software (Phillips et al., 2006). The HADCM3 A2 a climate change scenario (Collins et al., 2001) was used, which represents a grid point model that has a horizontal resolution of $3.75 \times 2.5$ degrees in longitude $\times$ latitude. This corresponds to a spacing between points of approximately $300 \mathrm{~km}$. Bioclimatic layers (see Table 1) in GIS compatible format were downloaded from the Worldclim website and used in the analysis.

Table 1. Different bioclimatic variables used in the simulation of $P$. roxburghii in Swat Hindukush range of Pakistan. (Source: WorldClim, 2011)

\begin{tabular}{c|c|c}
\hline S. No & Bio-climatic variables & Description \\
\hline 1 & bio-1 & Annual mean temperature \\
2 & bio-2 & Mean diurnal range (mean of monthly (max temp-min temp) \\
3 & bio-3 & Isothermality (100*mean diurnal range/annual temperature range) or (bio_2/bio_7*100) \\
4 & bio-4 & Temperature seasonality (standard deviation *100) \\
5 & bio-5 & Max temperature of warmest month \\
6 & bio-6 & Min temperature of coldest month \\
7 & bio-7 & Temperature annual range (bio_5 - bio_6) \\
8 & bio-8 & Mean temperature of wettest quarter \\
9 & bio-9 & Mean temperature of driest quarter \\
10 & bio-10 & Mean temperature of warmest quarter \\
11 & bio-11 & Mean temperature of coldest quarter \\
12 & bio-12 & Annual precipitation \\
13 & bio-13 & Precipitation of wettest month \\
14 & bio-14 & Precipitation of driest month \\
15 & bio-15 & Precipitation of wettest quarter \\
16 & bio-16 & Precipitation of driest quarter \\
17 & bio-17 & Precipitation of warmest quarter \\
18 & bio-18 & Precipitation of coldest quarter \\
19 & bio-19 &
\end{tabular}

\section{Results}

\section{Composition and structural patterns}

Among the 500 plots measured in 25 forest stands, 9 woody plants belonging to 8 families of 8 genera were identified and classified into 3 communities by cluster analysis (Fig. 2). These communities were clearly isolated in the nonmetric multidimensional scaling (NMS) ordination (results not shown). The summary of associated physiographic, and soil physical and chemical characteristics of these vegetation types were shown in Table 2. Group I was located at high elevations and slopes and low $\mathrm{pH}$, nitrogen $(\%), \mathrm{K}^{+}$, enriched with herbaceous species and grasses i.e. 
Viola biflora, Hetropogon cinata and Hetropogon species. Group II occurred at medium elevations and slopes, $\mathrm{pH}$ levels, and phosphorus contents with frequent Dodonea viscosa, Gymnosporia royleana, Plectranthus rugosus, Periploca aphylla, Teucrium stockcianum and Ajuga bracteosa. The Group III vegetation type mainly distributed at low elevations and comparatively high slopes with low $\mathrm{pH}$, Phosphorus and high organic matter, nitrogen (\%), and clay (\%); Dodonea viscosa, Indigofera gerardiana, Ajuga and Salvia were the common native species apart from the tree seedlings and saplings in the understory stratum.

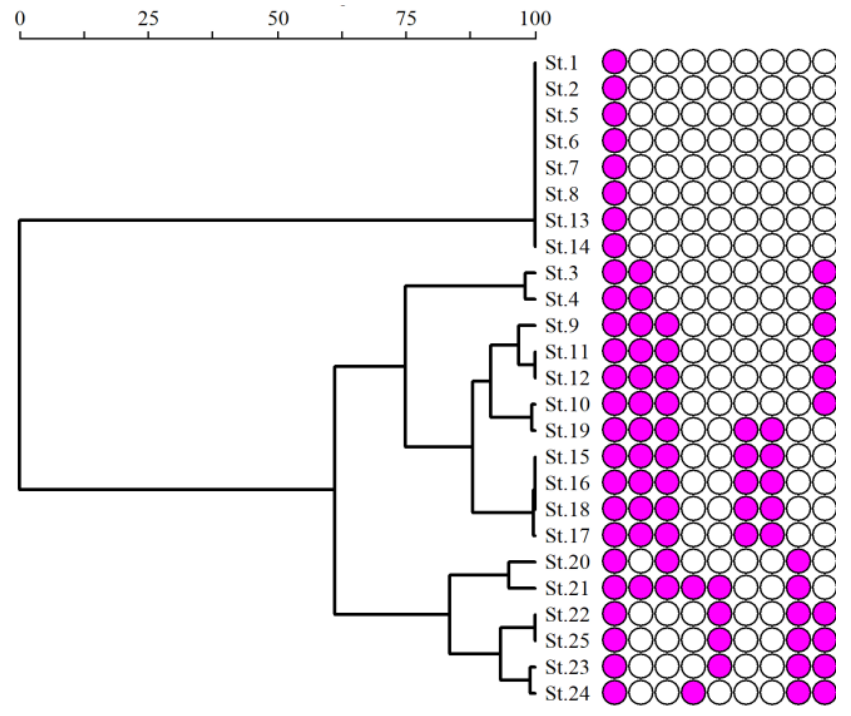

Figure 2. Ward's Agglomerative cluster analysis of 25 forest stands and 9 tree species grouped into three major vegetation types using quantitative Sorensen (Bray-Curtis) distance measure with a flexible beta $(\beta=-0.25)$ linkage extracted at $65 \%$ information

Table 2. Summary statistics of the Kruskal-Wallis test performed on environmental variables of the comparing tree communities

\begin{tabular}{c|c|c|c|c|c}
\hline Groups & I & II & III & \multirow{2}{*}{ H-statistics } & P-value \\
\cline { 1 - 3 } Dominant trees & P. roxburghii & $\begin{array}{c}\text { P. roxburghii } \\
\text { Q. incana }\end{array}$ & $\begin{array}{c}\text { P. roxburghii } \\
\text { A. modesta }\end{array}$ & & \\
\hline Elevation (m) & $1475 \pm 46.17$ & $1234 \pm 46.17$ & $1140 \pm 35.38$ & 6.51 & $\mathbf{0 . 0 3}$ \\
Slope ( $\left.{ }^{\circ}\right)$ & $34 \pm 1.37$ & $27 \pm 1.97$ & $29 \pm 2.11$ & 3.83 & $\mathbf{0 . 1 4}$ \\
Aspect & $4.87 \pm 0.91$ & $5.4 \pm 0.59$ & $7 \pm 0.68$ & 3.46 & $\mathbf{0 . 1 7}$ \\
Clay (\%) & $12.8 \pm 1.10$ & $12.5 \pm 0.69$ & $13.9 \pm 1.03$ & 1.25 & 0.53 \\
Silt (\%) & $13.4 \pm 1.23$ & $12.9 \pm 1.32$ & $16.8 \pm 2.08$ & 3.02 & $\mathbf{0 . 2 2}$ \\
Sand (\%) & $73 \pm 1.59$ & $72 \pm 1.59$ & $69 \pm 2.30$ & 3.08 & $\mathbf{0 . 2 1}$ \\
pH (1:5) & $6.81 \pm 0.21$ & $6.6 \pm 0.15$ & $6.9 \pm 0.20$ & 1.12 & 0.56 \\
Org. matter & $1.5 \pm 0.45$ & $1.2 \pm 0.26$ & $2.3 \pm 0.71$ & 2.21 & 0.33 \\
Lime (\%) & $4.4 \pm 1.07$ & $6.4 \pm 1.42$ & $4.0 \pm 0.93$ & 1.16 & 0.55 \\
N (\%) & $0.08 \pm 0.02$ & $0.10 \pm 0.03$ & $0.13 \pm 0.03$ & 1.20 & 0.54 \\
P (mg/kg) & $4.98 \pm 0.17$ & $5.5 \pm 0.22$ & $4.75 \pm 0.04$ & 7.32 & $\mathbf{0 . 0 2}$ \\
K (mg/kg) & $82.7 \pm 12.2$ & $81.5 \pm 8.9$ & $109 \pm 23.5$ & 0.79 & 0.67 \\
\hline
\end{tabular}

org. matter: organic matter, N: nitrogen, P: phosphorous, K: potassium; P-values (bold) are significant $\alpha=0.05$ 
Significant differences between the species composition $(\mathrm{A}=0.4037, \mathrm{P}<0.001)$, structural parameters (i.e. density; $A=0.3520, P<0.001$; basal area; $A=0.3260$, $\mathrm{P}<0.001)$ and environmental matrix $(\mathrm{A}=0.1865 ; \mathrm{P}<0.001)$ were obtained using MRPP. The result of cluster analysis was further clarified by a pair-wise comparison of the communities with high A-values recorded for Group I and II $(A=0.4508$, $\mathrm{P} \geq 0.001)$ and Group I and III $(\mathrm{A}=0.4106, \mathrm{P} \geq 0.001)$, whereas substantial similarity was found between Group II and III $(\mathrm{A}=0.1727, \mathrm{P}<0.001)$.

The average Importance values, density and basal areas for the tree species are presented in Tables 3 and 4 according to the Phytosociological groups. The plots from 8 forest sites contained a single species declared as mono-specific community (Group-I) of $P$. roxburghii with an average density of 634 individuals ha ${ }^{-1}$ and $47 \pm 7.66$ basal area $\mathrm{m}^{2} / \mathrm{ha}$. The proportion of saplings was higher $(25 \%)$ as compared to seedlings $(15 \%)$ and dead logs $(18 \%)$ which significantly contributed to the overall density in this community (Table 4).

Table 3. Importance values (Mean $\pm S E$ ) of tree species in three groups obtained from hierarchical cluster analysis

\begin{tabular}{c|c|c|c}
\hline Species & Group - I & Group - II & Group - III \\
\hline Pinus roxburghii & $100 \pm 00$ & $60.6 \pm 1.86$ & $58.33 \pm 2.1$ \\
Quercus incana & $-*$ & $16.8 \pm 3.18$ & $1.66 \pm 1.66$ \\
Quercus baloot & $-*$ & $9.0 \pm 2.0$ & $5 \pm 3.41$ \\
Acacia modesta & $-*$ & $-*$ & $15 \pm 2.23$ \\
Persia dutii & $-*$ & $-*$ & $2.5 \pm 1.70$ \\
Monotheca buxifolia & $-*$ & $-*$ & $6.66 \pm 2.1$ \\
Punica granatum & $-*$ & $5.27 \pm 1.92$ & $10.83 \pm 4.1$ \\
Olea ferruginea & $-*$ & $4.0 \pm 1.47$ & $-*$ \\
Ficus palmate & $-*$ & $4.0 \pm 1.47$ & $-*$ \\
\hline
\end{tabular}

$-* /$ - = absence

Group-II had eleven sites and 6 species dominated by $P$. roxburghii (IV $=60.6 \pm 1.86)$ and $Q$. incana (IV $=16.8 \pm 3.18)$, with a total density of 1231 individual's $\mathrm{ha}^{-1}$ and 35.31 basal area $\mathrm{m}^{2} / \mathrm{ha}$. The density of $P$. roxburghii and juveniles, i.e. seedlings and saplings was significantly lower as compared to Group I and III, respectively. However, dead trees shared $17 \%$ of the total tree density, which is comparatively higher than that of Group III, formed by six sites with seven species led by $P$. roxburghii $(\mathrm{IV}=58.33 \%)$ and Acacia modesta $(\mathrm{IV}=15 \%)$ in the arboreal forest (Table 2). The overall, density in this group is higher than the prior group (Group II) with an average density of 502 individuals/ha and 25.6 basal area $\mathrm{m}^{2} / \mathrm{ha}$ of the dominant species. The main companions in these communities are $Q$. baloot with an average IVI that ranged from $5-9.0 \%$ followed by Punica granatum and Monotheca buxifolia. All these species contributed $<2 \%$ density and basal area in these communities. However, Olea ferruginea, Ficus palmata, $P$. dutii and $P$. granatum were minor associates with $<5 \%$ of IVI and $1 \%$ density ha ${ }^{-1}$ and basal area $\mathrm{m}^{2} /$ ha (Tables 3 and 4 ).

\section{Vegetation-environment relationship}

Twelve environmental factors measured were used in CCA to explore the patterns of species distribution. The correlation among the environmental variables showed 
virtually total independence, which generally, simplifies the interpretation of the present results. The iteration report showed that a stable solution was quickly found with a tolerance level of $0.100000 \mathrm{E}-12\left(=10^{-13}\right)$ after 22,55 and 18 iterations for the first three canonical axes, respectively. The unrestricted Monte Carlo test permutation $F$. ratios showed strong relationship between the matrices, i.e. eigen-values $(P=0.0190)$ and species-environment $(P=0.0480)$ correlation, indicating that observed patterns did not arise by chance. The results of the first three axes explained $49.3 \%$ of the variability in species data, of which $26.6 \%$ was accounted for the first axis. The results indicated a significant correlation between species and environmental variables in the first CCA axis $(R=0.913, \mathrm{P}=0.02)$. The results of canonical coefficients revealed that physiographic (elevation, aspect), soil physical (sand, silt, and clay) and chemical (lime and $\mathrm{P}$ ) factors were the major variables in the first axis, whereas, potassium $\left(\mathrm{K}^{+}\right)$ dominate the third axis. The bi-plot species data shows the species that have greater loading on the axes, are $Q$. baloot, $O$. ferruginea, $F$. palmata and $Q$. incana which occupied the negative end of Axis 1, whereas, A. modesta, P. dutii and M. buxifolia occupied the lower and $P$. roxburghii the upper positive ends respectively (Fig. 3). This means that the positive axis species are extending their population while the negative axis species showed a similar underlying gradient but in an opposite direction to $P$. roxburghii along different environmental regimes in the study area.

Table 4. Average density/ha and basal area $\mathrm{m}^{2} / \mathrm{ha}$ of living and dead trees of $P$. roxburghii in the three groups. Only the density of seedling, sapling and dead tree of P. roxburghii are shown

\begin{tabular}{c|c|c|c|c|c|c}
\hline \multirow{2}{*}{ Species } & \multicolumn{2}{|c|}{ Group - I } & \multicolumn{2}{c|}{ Group - II } & \multicolumn{2}{c}{ Group - III } \\
\cline { 2 - 7 } & Dha $^{-\mathbf{1}}$ & $\begin{array}{c}\mathbf{B A} \\
\mathbf{m}^{\mathbf{2}} \mathbf{h} \mathbf{-}^{-\mathbf{1}}\end{array}$ & $\mathbf{D h a}^{-\mathbf{1}}$ & $\begin{array}{c}\mathbf{B A} \\
\mathbf{m}^{\mathbf{2}} \mathbf{h a}^{-\mathbf{1}}\end{array}$ & $\mathbf{D h a}^{-\mathbf{1}}$ & $\begin{array}{c}\mathbf{B A} \\
\mathbf{m}^{\mathbf{2}} \mathbf{h a}^{-\mathbf{1}}\end{array}$ \\
\hline Pinus roxburghii & $634 \pm 00$ & $47 \pm 7.66$ & $433 \pm 34.0$ & $19.6 \pm 6.4$ & $512 \pm 28.1$ & $25.6 \pm 8.9$ \\
Quercus incana & $-*$ & - & $55 \pm 10.1$ & $8.4 \pm 3.6$ & $10 \pm 5.60$ & $1.27 \pm 0.22$ \\
Quercus baloot & - & - & $17 \pm 7.0$ & $4.9 \pm 2.0$ & $20 \pm 6.40$ & $5.33 \pm 3.1$ \\
Acacia modesta & - & - & - & - & $22 \pm 8.21$ & $3.81 \pm 1.8$ \\
Persia dutii & - & - & - & - & $5 \pm 2.72$ & $0.01 \pm 0.2$ \\
Monotheca buxifolia & - & - & - & - & $13 \pm 6.3$ & $2.81 \pm 1.9$ \\
Punica granatum & - & - & $12 \pm 4.94$ & $1.45 \pm 2.4$ & $16 \pm 7.5$ & $2.55 \pm 1.7$ \\
Olea ferruginea & - & - & $10 \pm 3.6$ & $0.89 \pm 0.44$ & - & - \\
Ficus palmate & - & - & $7.0 \pm 2.40$ & $0.07 \pm 0.04$ & - & - \\
Seedlings & $234 \pm 45$ & $\mathrm{Nc}$ & $187 \pm 66$ & $\mathrm{Nc}$ & $209 \pm 88$ & $\mathrm{Nc}$ \\
Saplings & $377 \pm 57$ & $\mathrm{Nc}$ & $299 \pm 105$ & $\mathrm{Nc}$ & $266 \pm 67$ & $\mathrm{Nc}$ \\
Dead trees & $276 \pm 79$ & $\mathrm{Nc}$ & $211 \pm 59$ & $\mathrm{Nc}$ & $188 \pm 78$ & $\mathrm{Nc}$ \\
Total & 1522 & 47 & 1231 & 35.31 & 1261 & 41.38 \\
\hline
\end{tabular}

-*/- = absence, $\mathrm{Dha}^{-1}=$ density per hectare, $\mathrm{BA} \mathrm{m}^{2} \mathrm{ha}^{-1}=$ basal area meter square per hectare, $\mathrm{Nc}=$ not count

\section{Diameter patterns}

The diameters of $P$. roxburghii distributed in different stands were pooled based on cluster analysis and presented in the form of histograms that show a unimodal pattern (Fig. 4a-c). The mean diameter of the species was 8.1, 7.8 and $8.7 \mathrm{~cm}$ in Group I, II and III, respectively (Table 5). The standard deviation around the means was approximately 
$2.3 \mathrm{~cm}$ for all the groups. The values for scale parameter ( $\alpha$ and $\beta$ ) roughly followed the distribution diameter means, fitting the Weibull function as expected. The shape statistics for $P$. roxburghii in Group I was $\alpha=4$.1, for Group II $\alpha=3.6$, and Group III individuals was $\alpha=3.8$ respectively show that diameter distribution for $P$. roxburghii populations in all the groups are generally skewed. Results of the K-S test for function fitting are provided in Table 5 indicating that the 2 parameters of Weibull function suggest the lowest mean values for the diameter distributions of $P$. roxburghii in all groups.

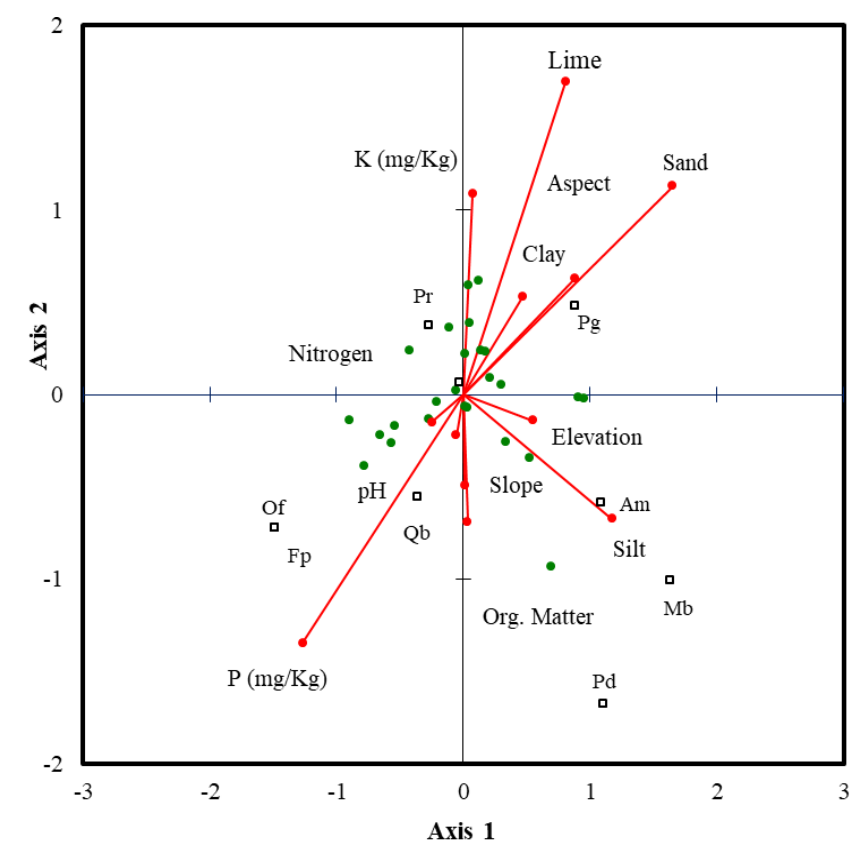

Figure 3. Sites-environment on the bi-plot of CCA ordination of 25 forest stands. The eigenvalue for axis 1 was 0.22 and for axis 2 was 0.10
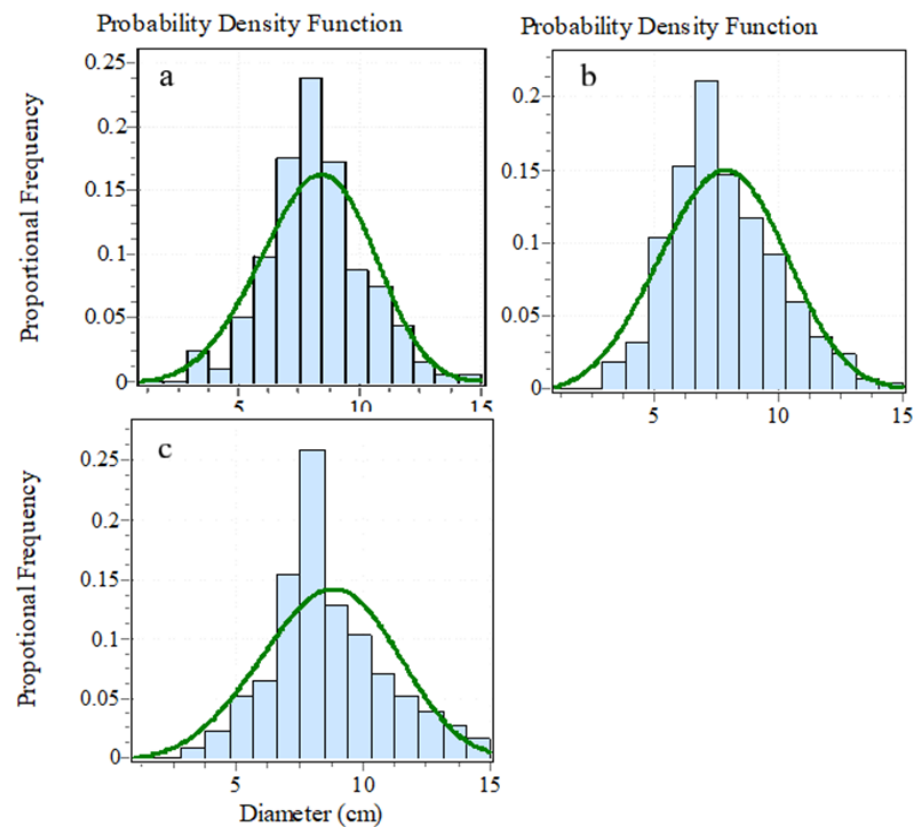

Figure 4. a-c Diameter class histograms and corresponding fitted Weibull distribution for three groups of $P$. roxburghii 
Table 5. Representing, samples size $(N)$, mean diameter $( \pm S D)$, Weibull shape $(\alpha)$ and scale parameters $(\beta)$ with $K-S$ goodness of fit summary

\begin{tabular}{c|c|c|c|c|c}
\hline Groups & $\begin{array}{c}\text { No. of } \\
\text { samples (N) }\end{array}$ & $\begin{array}{c}\text { Mean diameter } \\
(\mathbf{X})\end{array}$ & $\begin{array}{c}\text { Shape } \\
\text { parameter }(\boldsymbol{\alpha})\end{array}$ & $\begin{array}{c}\text { Scale parameter } \\
(\boldsymbol{\beta})\end{array}$ & $\begin{array}{c}\text { Kolmogorov- } \\
\text { Smirnov (K-S) }\end{array}$ \\
\hline I & 801 & $8.2 \pm 2.1$ & 4.1 & 9.0 & 0.14 \\
II & 854 & $7.8 \pm 2.3$ & 3.6 & 8.6 & 0.14 \\
III & 774 & $8.7 \pm 2.3$ & 3.8 & 9.6 & 0.16 \\
\hline
\end{tabular}

\section{Age and growth rate patterns}

Age structure and growth rate pattern of $P$. roxburghii in different vegetation types (Group I-III) indicated a pattern similar to that of diameter. Bell-shaped age distribution was found in Group I, where the juvenile stages, i.e. $1-10 \mathrm{~cm}$ and $10-20 \mathrm{~cm}$ classes, accounted for 3 to $4 \%$ and 6 to $8 \%$ of the total individuals. Substantial numbers of individuals were young (58\%) while old trees (>100 years) were rarer (13\%) in this group. The mean annual increment was $5.0(\mathrm{SD}= \pm 2.92 \mathrm{~cm})$ which is higher than that of the other forest groups located in the area. Comparing Group II with prior (Group I) and proceeding group (Group III), the age structure was generally different. In Group II the youngest individuals were comparable (14\%) while young were predominant, becoming $64 \%$ of the total. Only $10 \%$ of the individuals were between the ages ranged from 100140 years (Fig. 5), and old trees above this range were entirely absent. Mean annual increment was $3.8 \pm 1.92 \mathrm{~cm}$ which is higher than the individuals in the prior group.

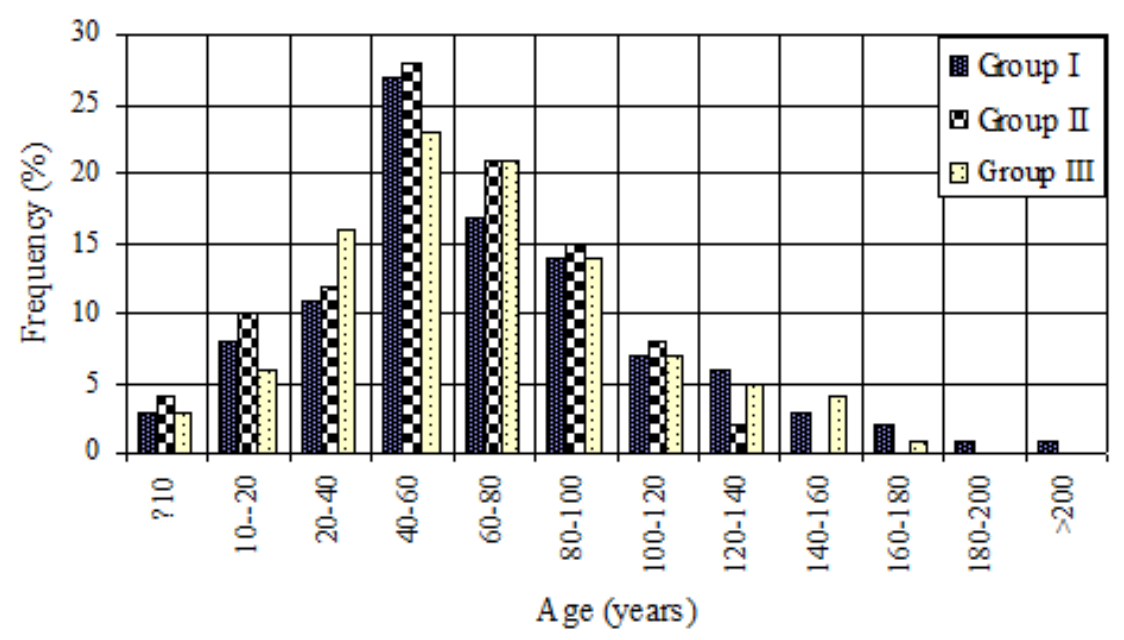

Figure 5. The age structure of P. roxburghii populations in different groups

Group III, shared a similar proportion of individuals in the youngest category (9\%), while the majority $(48 \%)$ of them were between 40 and 100 years old. Old trees $(>100)$ were rare and no individuals were found $>180$ years old, followed an almost bellshaped pattern. Mean annual increment of $P$. roxburghii was $2.7 \pm 0.98$ which is highest among all the groups. Statistically, significant relationships were obtained between age and diameter $(y=0.053 \mathrm{x}-58.001 ; \mathrm{R}=0.852 \quad P<0.001)$ and age and height $(y=0.0453 \mathrm{x}-50.002 ; \mathrm{R}=0.810 ; \mathrm{P}<0.001)$ of $P$. roxburghii in the entire groups using regression equations. 


\section{Predictive modeling}

MaxEnt predicted the existing distribution of $P$. roxburghii as restricted to the south of the valley due to its significantly higher population density in these areas (Fig. 6a) whereas, the future distribution model shows even worse situation for the species, i.e., the entire shift of population is to the neighbouring district located in the west. Only a few patches at the western border may still survive because of the favourable conditions available at the end of the century (Fig. $6 b$ ). Ground-truth surveying (qualitative) was carried out to check the validity of the present predictive model. The Jackknife analysis (JA) of the present probability distribution of the area under cover (AUC) for the species indicates that all environmental variables are contributing to the AUC (over 0.80) except bio-7 (Temperature annual range), which has a very small share in the gain of AUC. The highest contribution was recorded for climatic variable bio-19 which is the precipitation of the coldest quarter (Fig. 7).

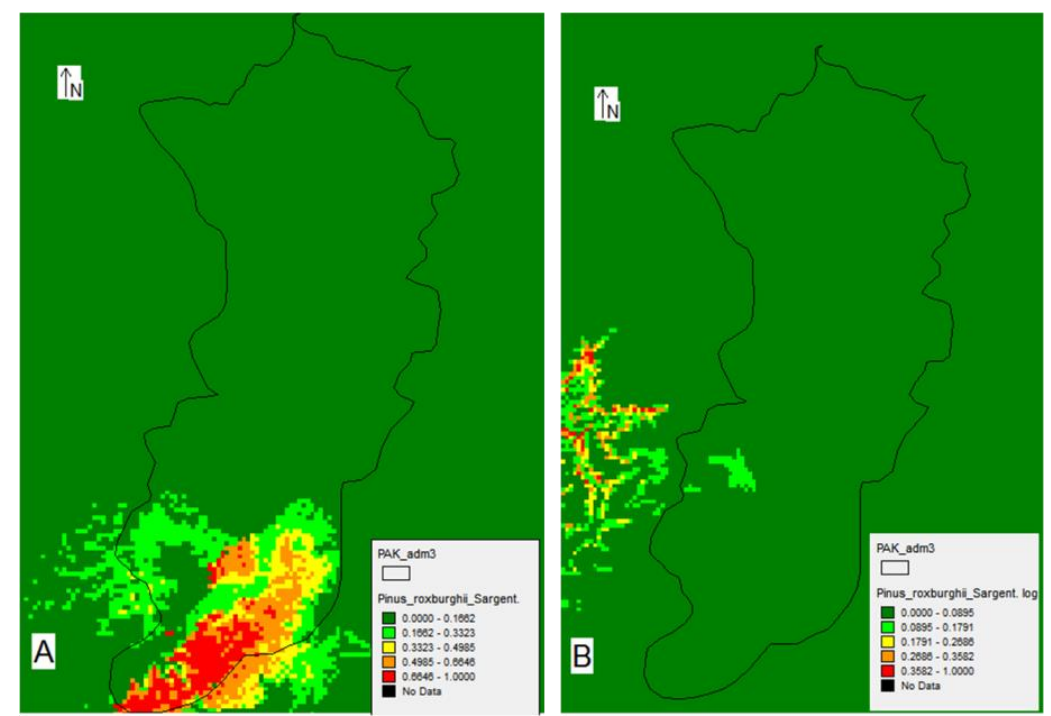

Figure 6. a Present predicted distribution of P. roxburghii. $\boldsymbol{b}$ Future projected distribution of $P$. roxburghii

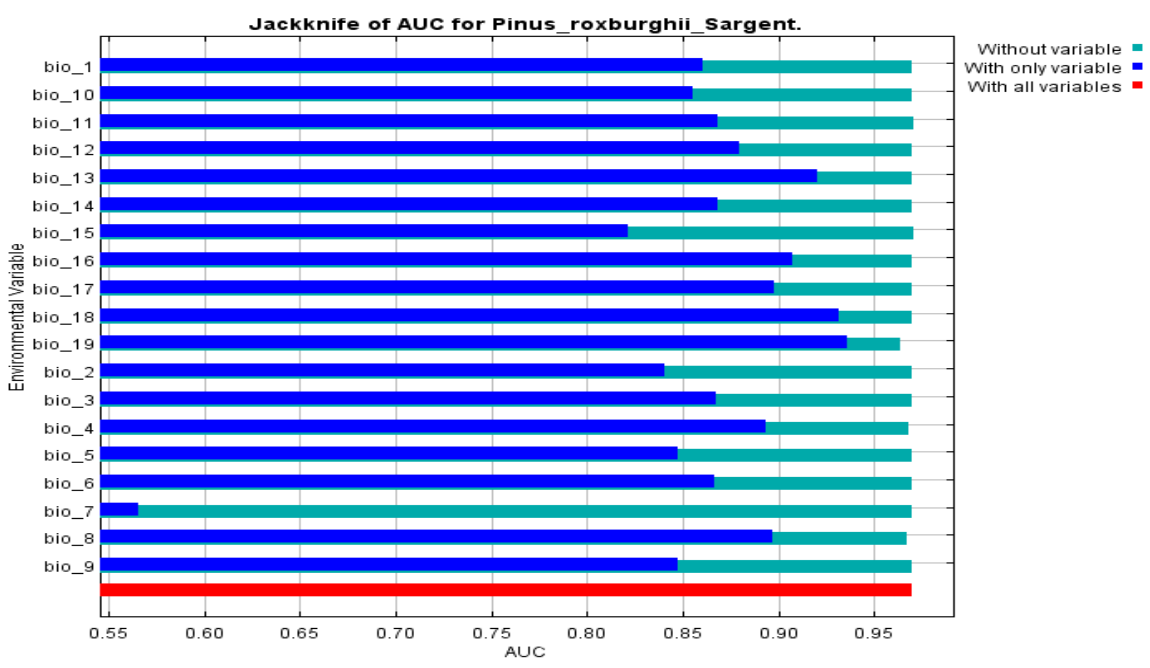

Figure 7. Jackknife of AUC for P. roxburghii, present distribution model 
The sensitivity and 1- specificity graph shows the best fit of the model with gain of 0.977 and 0.970 gain for AUC of training and test data, respectively (Fig. 8). The figure also clearly indicates the best fit of the model; both training and test omission that are very close with each other and close to the predicted omission (threshold of 0.5 ). In the future prediction model of $P$. roxburghii, the trend remains the same; the most important variable was found to be bio-19 and the least contributor was bio-7 (Figs. 9 and 10).

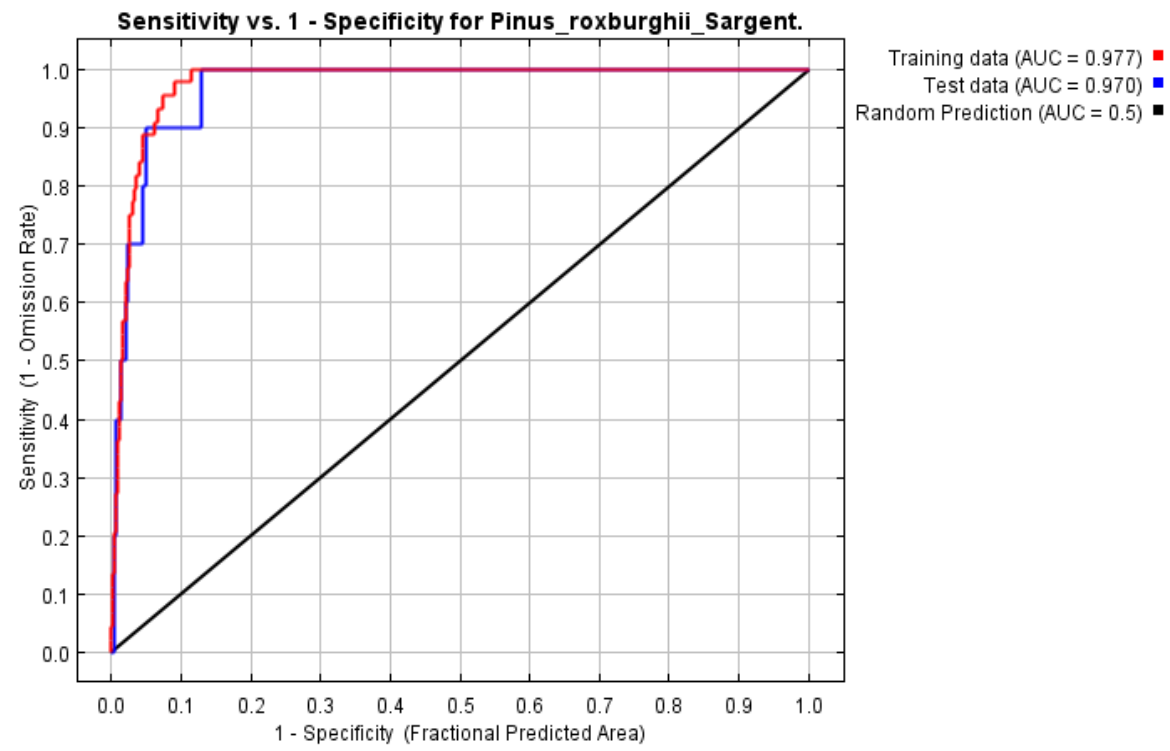

Figure 8. Sensitivity and 1- specificity for P. roxburghii for present distribution model

\section{Discussion}

Variability of environmental conditions could lead to spatial segregation of the flora and structural alterations in plant communities (Dufour et al., 2006). In the present subtropical pine forest, we have identified three distinct plant communities that vary considerably in species composition and occupied different ecological niches in this region. Contrary to monospecific community of $P$. roxburghii (Group I), P. roxburghii and $Q$. incana association (Group II) appeared to prefer medium elevation, degree of slopes, sand (\%), $\mathrm{pH}$ and potassium, while $P$. roxburghii and $A$. modesta preferred the sites with low elevations, $\mathrm{pH}$, lime (\%) and high physical and chemical properties (Table 2). $P$. roxburghii, typically as a pure community, was mainly restricted to relatively high elevation slope sites, with low amount of clay, silt, nitrogen (\%) lime (\%) and potassium content. It has been reported by Siddiqui et al. (2009) that P. roxburghii mostly occurs as pure populations in most of the forest patches in northern Pakistan. However, on some drier hill sites it is associated with broadleaved and deciduous tree species like $O$. ferruginea, $M$. buxifolia, $P$. granatum and $F$. palmata in low and middle elevation zones (Khan et al., 2014). Several, other studies of vegetation classification were also conducted in Hindukush and Himalayan mountain ranges in Pakistan, showing that $P$. roxburghii occurs as a pure community and also a dominant associate with broadleaved and deciduous trees almost in the same elevation ranges (Malik et al., 2007; Nafeesa et al., 2007). These results correspond to our findings owing to similar ecogeographical regions. However, in neighboring countries like India, Nepal, and Bhutan 
this species is restricted to the Monsoon belt with summer rain forming associations with $P$. ponderosa, $Q$. leucotricophora and $Q$. semecarpifolia etc., which may be due to the different climate regimes and eco-geographical regions. These differences indicate that vegetation structure, community pattern and differential species distribution are affected by a broad array of biotic, environmental and climatic interactions that overlap and govern community structure in a complex manner (Sarker et al., 2014).

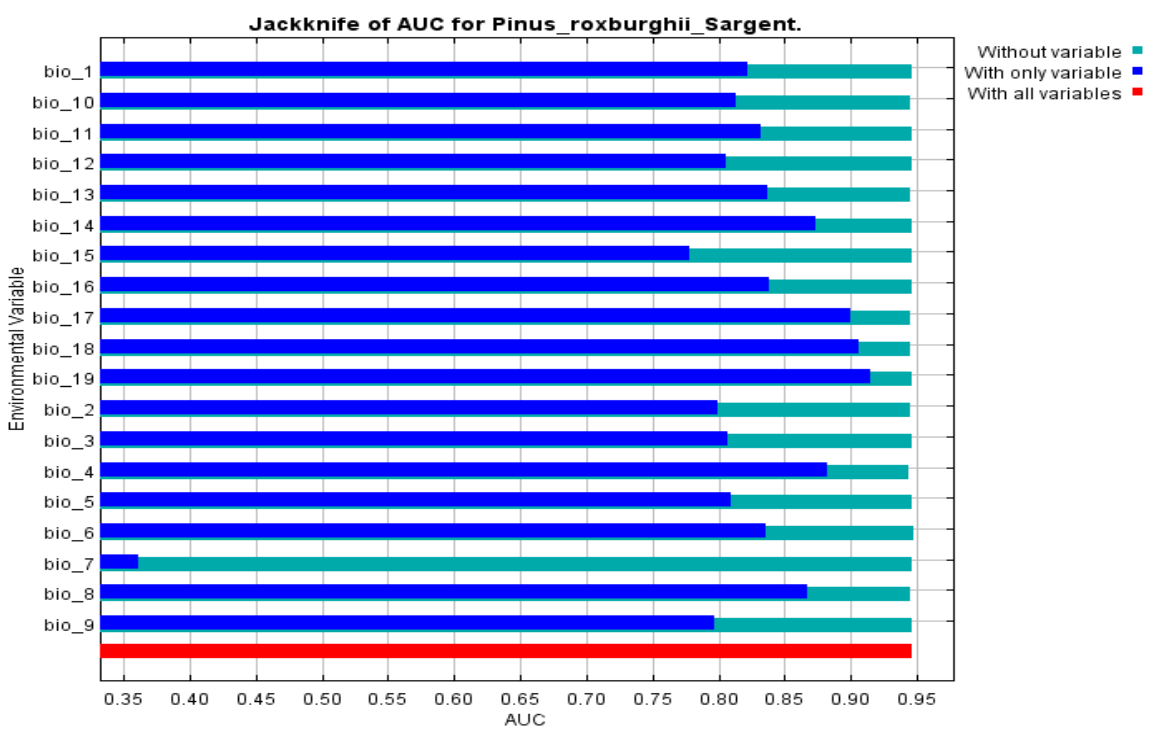

Figure 9. Jackknife of AUC for P. roxburghii, future prediction model

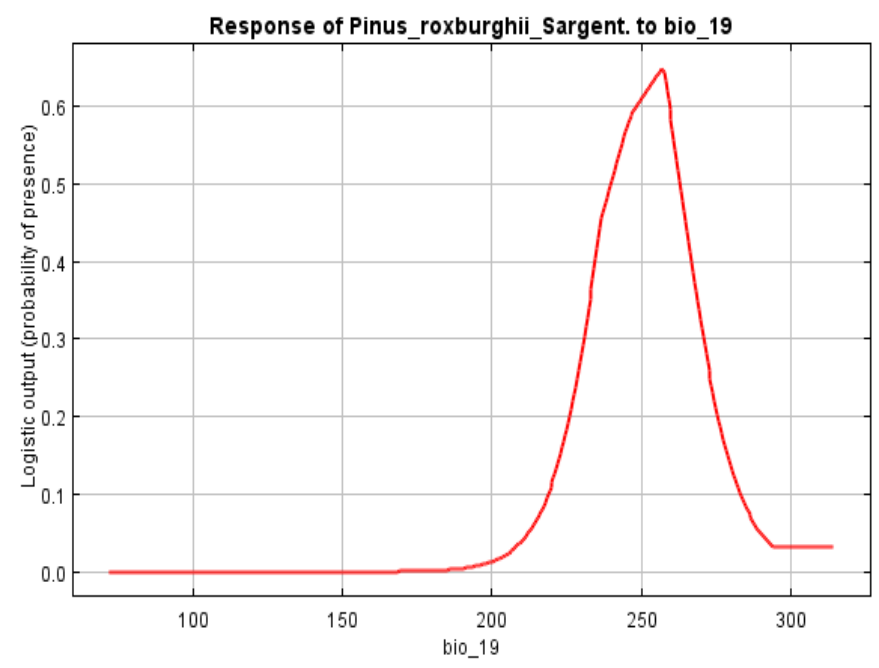

Figure 10. P. roxburghii showing response to bioclimatic variable-19 (precipitation of coldest quarter) for future prediction

In subtropical forests, natural vegetation often responds to several gradients simultaneously and different combinations of gradients produce divergent responses to the set of gradients (Khan et al., 2013). Our results of ordination support such a continuum and indicate that spatial distribution patterns of $P$. roxburghii associations do 
not follow a single environmental gradient, rather, an assortment of gradients account for its compositional variation. This variation could be attributed to physiographic (e.g. elevation, aspect), soil physical (e.g. clay, silt and sand particles) and chemical properties (lime and P) as found previously (Siddiqui et al., 2009; Ahmed et al., 2011; Khan et al., 2014) or climatic variables (Ali et al., 2014). These results show that species composition was affected not only by physiographic but also by soil properties, probably due to high variability of the sub-alpine and alpine environments (Champion et al., 1965; Marini et al., 2007). The ordination bi-plot species data shows that species with greater loading on the axes are $Q$. baloot, O. ferruginea, $F$. palmata and $Q$. incana which occupied the negative end of Axis 1, whereas, A. modesta, P. dutii, and $M$. buxifolia the upper positive end along with $P$. roxburghii. Such a distribution pattern shows that positive axis species are extending their populations while the negative axis species show a similar underlying gradient but in the opposite direction to $P$. roxburghii along different environmental regimes. These compositional changes in the current forests seem to be governed by altitudinal gradient acting as an elevation driver among the physiographic factors responsible for compositional variation in the high mountains range (Hong et al., 2015). Several factors like temperature, humidity, snowfall, solar radiation, etc. are associated with elevation, as demonstrated by several authors (e.g., Rana et al., 2011).

Few forest stands with trees in excess of $>110 \mathrm{~cm}$ DBH were observed in subtropical $P$. roxburghii forests and the majority are represented by trees $<50 \mathrm{~cm}$ DBH. Ahmed et al. (2006) suggest that the majority of mature subtropical pine forests have basal area values that fall within the range of $25-32 \mathrm{~m}^{2} / \mathrm{ha}$ (based only on stems $\geq 10 \mathrm{~cm} \mathrm{DBH}$ ). The maximum observed basal area in $P$. roxburghii for any one stand, was $41.0 \mathrm{~m}^{2} / \mathrm{ha}$; this exceeds most observed values in other mature pine and coniferous forests in northern Pakistan and even in the neighboring countries (Siddiqui et al., 2009; Khan et al., 2011; Ahmed et al., 2011). All but one vegetation type (oakolea) fall within or above the range of basal area suggested by Khan (2012) as being indicative of structural maturity in subtropical forests of northern Pakistan. The analysis of forest disturbance history from nondestructive sampling techniques is generally difficult, but DBH distributions may be useful for differentiating among broad-scale differences in stand structure (McCarthy et al., 1987).

The basal area results were confirmed by diameter size analysis, which indicted that all of the communities examined had a unimodal (Bell shaped) distribution, most likely due to high mortality or growth suppression of individuals in the smaller and greater size classes. It has been observed that $P$. roxburghii grow rapidly in height and diameter at early stage of life, with growth rate decreasing with age (Personal observations). In the current study the mean annual increment in the diameter $\geq 10$ and $\leq 110$ was $5.0 \pm 2.92$ in the highlands, $3.8( \pm 1.92)$, at middle elevations and $2.7( \pm 0.98)$ years $/ \mathrm{cm}$ in the lowlands. These values indicated that $P$. roxburghii growth is also sensitive to climate as climatic parameters vary considerably on high altitude (Wang et al., 2004; Huang and Zhang, 2007). Strong relationships were obtained between diameter and age and growth rates, analogous to previous studies (e.g., Khan et al., 2014). Generally, the predication of diameter distribution of stands is of great interest to forest managers for the evaluation of forest resources and predicting future silvicultural treatments (Nano and Montero, 2002). Hence, the use of appropriate statistical models play an important role (Sheykholeslami et al., 2011) by indicating whether the density of smaller trees in a stand is sufficient to replace the current population of larger trees and to help evaluate 
potential forest sustainability (Rubin and Manion, 2006). We used the three-parameter Weibull function in the present study, which proved effective for fitting the diameter distributions of pine forests. This work will provide baseline information and will substantially increase our knowledge of diameter distributions of pine forests in northern Pakistan. The proposed model diameter distribution will be exceedingly useful for further inventories and the management of these forests as the present study was the first attempt in the area. Other species found in the present study including $Q$. incana, $O$. ferruginea, A. modesta, $P$. granatum and $M$. buxifolia, were all present as overstory and understory except in Group I, but at low densities. $Q$. incana and $P$. granatum have been shown to establish themselves in open canopy on northern aspects. However, their ability to replace $P$. roxburghii cannot be predicted from the present study, although it seems likely. Due to low sample size Weibull function for these species was not interpreted.

It is now a well-established fact that the climate change is real and the average global temperature in on the rise affecting organisms in one way or another (IPCC, 2013; Root et al., 2003). Generally, organisms show a well pronounced response to the change though the fact that some responses are less pronounced or remain unknown requires dedicated scientific investigations. The current study concludes that most of the tree species in the District will respond to the changing climate in the area and will either shift their habitats, reduce/increase their distribution or in some cases go extinct in the area. In corroboration with the findings of Song et al. (2004), altitude had significant effect on the distribution of species. They have also reported the effect of climate change on the northward movements of the tree species, including Abies spp. and Picea spp. The variable Bio-19 (precipitation of the coldest quarter) was found to be the most important variable in the present predictive distribution model of $P$. roxburghii. This environmental variable remains equally important for the future predictive model of $P$. roxburghii distribution. Another personal observation related to $P$. roxburghii is that it is the most preferred plant by the Forest Department of Pakistan for the purpose of reforestation, but the future distribution model tells a different story about the future of the species i.e., extreme reduction in distribution. It is evident from the results of the study that the associated species with $P$. roxburghii will have considerable impact on its distribution and density in the future but this warrants further studies to evaluate the impact of reduction and loss of this important plant on the other plant species and communities.

\section{Conclusions}

The use of numerical methods and species distribution model (SDM) were exceedingly useful in the exposition of the current classification, compositional variation with relation of environmental factors and in simulating the future distribution trend of $P$. roxburghii communities in Swat Hindukush range of Pakistan. In this paper, we described the first comprehensive investigation into environmental factors that significantly affect the distribution $P$. roxburghii communities in a priority conservation area of northern Pakistan renowned for eco-tourism. Despite the low variance in the data explained, the studied variables provide useful insight on plant distribution. Thus, the research approach demonstrated here can help in conserving the remaining natural patches of the forest by providing a basis for vegetation monitoring, mapping and assessing site qualities a priori. 
Acknowledgements. We thank Dr. Siraj Ahmad Yousfzai, Dr. Inayat-Ur-Rahman, Dr. Muammad Irshad and students and staff at the Jehanzeb Postgradute College Swat for helping in the fieldwork; Dr. Gulzar, Forest Divisional Officer (DFO) for permission to collect tree core samples; technicians at Swat Agriculture Research Centre for performing soil analyses; and Dr. Ali Hazrat for identifying plant specimens. We also thank Mr. Rafi Ullah for help in formatting tables, and three anonymous referees for reviewing the manuscript.

\section{REFERENCES}

[1] Abdelaal, M., Fois, M., Fenu, G., Bacchetta, G. (2019): Using MaxEnt modeling to predict the potential distribution of the endemic plant Rosa arabica Crép. in Egypt. Ecological Informatics 50: 68-75. https://doi.org/10.1016/j.ecoinf.2019.01.003.

[2] Ahmed, M., Hussain, T., Sheikh, A. H. (2006): Phytosociology and structure of Himalayan forest from different climatic zones of Pakistan. - Pak J Bot 38: 361-382.

[3] Ahmed, M., Shaukat, S. S., Saddiqui, M. F. (2011): A multivariate analysis of vegetation of Cedrus deodara forests in Hindukush and Himalayan ranges of Pakistan: evaluating the structure and dynamics. - Turk J Bot 35: 419-438.

[4] Ali, K., Ahmad, H., Khan, N., Jury, S. (2014): Future of Abies pindrow in Swat district, northern Pakistan. - Journal of Forestry Research 25: 211-214.

[5] Ashraf, U., Ali, H., Chaudry, M. N., Ashraf, I., Batool, A., Saqib. Z. (2016): Predicting the potential distribution of Olea ferruginea in Pakistan incorporating climate change by using Maxent model. - Sustainability 8: 722. https://doi.org/10.3390/su8080722.

[6] Barry, J. P., Baxter, C. H., Sagarin, R. D., Gilman, S. E. (1995): Climate related long term faunal changes in California rocky intertidal community. - Science 267: 672-675.

[7] Bremner, J. M., Mulvaney, C. S. (1982): Nitrogen-Total. - In: Page, A. L., Miller, R. H., Keeney, D. R. (eds.) Methods of Soil Analysis. Part 2, Chemical and Microbiological Properties. 2nd Ed. American Society of Agronomy, Madison, WI, pp. 595-624.

[8] Champion, G. H., Seth, S. K., Khattak, G. M. (1965): Forest Types of Pakistan. Pakistan Forest Institute, Peshawar, Pakistan, pp. 111-144.

[9] Collins, M., Tett, S., Cooper, C. (2001): The internal climate variability of HADCM3, a version of the Hadley center coupled model without flux adjustments. - Climate Dynamics 17: 61-68.

[10] Condit, R., Perez, R., Daguerre, N. (2011): Trees of Panama and Coast Rica. - Princeton University Press, Princeton, NJ.

[11] Curtis, J. T., McIntosh, R. P. (1950): The interrelation of certain analytic and synthetic phytosociological characters. - Ecology 31: 434-455.

[12] Dufour, A., Gadallah, F., Wagner, H. H. (2006): Plant species richness and environmental heterogeneity in a mountain landscape: effects of variability and spatial configuration. Ecography 29: 573-584.

[13] Elith, J., Graham, C. H., Anderson, R. P., Dudík, M., Ferrier, S., Guisan, A., Hijmans, R. J., Huettmann, F., Leathwick, J. R., Lehmann, A., Li, J., Lohmann, L. G., Loiselle, B. A., Manion, G., Moritz, C., Nakamura, M., Nakazawa, Y., Overton, J. M., Peterson, A. T., Phillips, S. J., Richardson, K., Scachetti-Pereira, R., Schapire, R. E., Soberón, J., Williams, S., Wisz, M. S., Zimmermann, N. E. (2006): Novel methods improve prediction of species' distributions from occurrence data. - Ecography 29: 129-51.

[14] Hill, M. O., Gauch, H. G. (1980): Detrended correspondence analysis: an improve ordination technique. - Vegetatio 42: 47-58.

[15] Hong, H., Qi, F., Yong-hong, S. (2015): Shrub communities and Environmental variables responsible for species distribution patterns in an alpine zone of the Qilian Mountains, Northwest China. - J Mt Sci-Engl 12: 166-176.

[16] Huang, J. G., Zhang, Q. B. (2007): Tree rings and climate for the last 680 years in Wulan area of northeastern Qinghai-Tibetan Plateau. - Climatic Change 80: 369-377. 
[17] I.P.C.C. (2013): Climate Change 2013: The Physical Science Basis. - Cambridge University Press, Cambridge.

[18] Kamyo, T., Asanok, 1. (2020): Modeling habitat suitability of Dipterocarpus alatus (Dipterocarpaceae) using MaxEnt along the Chao Phraya River in Central Thailand. Forest Science and Technology 16: 1-7. DOI: 10.1080/21580103.2019.1687108.

[19] Khan, N. (2012): A community analysis in Quercus baloot Griff, forest District Dir Upper Pakistan. - African Journal of Plant Science 6: 21-31.

[20] Khan, N., Ahmed, M., Shaukat, S. S., Wahab, M., Siddiqui, M. F. (2011): Structure, diversity and regeneration potential of Monotheca buxifolia (Falc.) A. DC. dominated forests of Lower Dir District, Pakistan. - Frontier of Agriculture in China 5: 106-121.

[21] Khan, N., Shaukat, S. S., Ahmed, M., Siddiqui, M. F. (2013): Vegetation-environment relationships in the forests of Chitral district Hindukush range of Pakistan. - Journal of Forestry Research 24: 205-216.

[22] Khan, N., Ali, K., Shaukat, S. S. (2014): Phytosociology, structure and dynamics of Pinus roxburghii associations from Northern Pakistan. - Journal of Forestry Research 25: 511521.

[23] Khan, W., Hussain, M., Ali, K., Ali, M., Nisar, M. (2020): Distribution and phenotypic variation in Juglans regia L. growing in Hindu Kush ranges of Pakistan. - Acta Ecologica Sinica 40(5): 363-372. https://doi.org/10.1016/j.chnaes.2020.02.009.

[24] Lance, G. N., Williams, W. T. (1967): A general theory of classification sorting strategies. II. Clustering strategies. - Comput J 10: 271-7.

[25] Legendre, P., Legendre, L. (1998): Numerical Ecology. 2nd Ed. - Elsevier, Amsterdam.

[26] Li, P., Zhu, W., Xie, Z., Qiao, K. (2019): Integration of multiple climate models to predict range shifts and identify management priorities of the endangered Taxus wallichiana in the Himalaya-Hengduan Mountain region. - Journal of Forestry Research. https://doi.org/10.10 07/s11676-019-01009-5.

[27] Malik, N. Z., Arshad, M., Sarwat, N. M. (2007): Phytosociological attributes of different plants communities of Pir Chinasi hills of Azad Jammu and Kashmir. - Int J Agric Biol 9: 569-574.

[28] Marini, L., Scotton, M., Klimek, S., Johannes, I., Angelo, P. (2007): Effect of local factors on plant species richness and composition of Alpine meadows. - Agri Ecosyst Environ 119: 281-288.

[29] McCarthy, B. C., Hammer, C. A., Kauffman, G. L., Cantiona, P. D. (1987): Vegetation structure and pattern of an old-growth forest in southeastern Ohio. - Bulletin of the Torry Botanical Club 114: 33-45.

[30] McCune, B., Grace, J. B. (2002): Analysis of Ecological Communities. - MjM software Design, Gleneden Beach, OR.

[31] Miehe, G., Miehe, S., Schlutz, F. (2009): Early human impact in the forest ecotone of southern high Asia (Hindu Kush, Himalaya). - Quaternary Res 71: 255-265.

[32] Nafeesa, Z., Malik, M., Arshad, S. M. N. (2007): Phytosociological attributes of different Plant communities of Pir Chinasi hills of Azad Jammu and Kashmir. - Int J Agric Biol 9: 565-574.

[33] Nano, N., Montero, G. (2002): Spatial prediction of diameter distributions models. Forest Ecol Manag161: 147-158.

[34] Ogden, J., Ahmed, M. (1989): Climate response function analysis of Kauri (Agathis australis) tree-ring chronologies in northern New Zealand. - J Roy Soc New Zeal 19: 205-221.

[35] Olsen, S. R. (1954): Estimation of Available Phosphorus in Soils by Extraction with Sodium Bicarbonate (No. 939). - US Department of Agriculture, Washington.

[36] Phillips, S. J., Anderson, R. P., Schapire, R. E. (2006): Maximum entropy modeling of species geographic distributions. - Ecol Model 190: 231-259. 
[37] Rana, M. S., Samant, S. S., Rawat, Y. S. (2011): Plant communities and factors responsible for vegetation pattern in an alpine area of the northwestern Himalaya. - J Mt Sci-Engl 8: 817-826.

[38] Rigg, L. S., Enright, N. J., Jaffre, T. (1998): Stand structure of the emergent conifer Araucaria laubenfelsii, in Maquis and rainforest, Mont Do, New Caledonia - Aust J Ecol 23: 528-538.

[39] Root, T. L., Price, J. T., Hall, K. R., Schneider, S. H., Rosenzweig, C., Pounds, J. A. (2003): Finger prints of global warming on wild animals and plants. - Nature 421: 57-60.

[40] Rubin, B. D., Manion, P. D., Faber, L. (2006): Diameter distributions and structural sustainability in forests. - Forest Ecol Manag 222: 427-438.

[41] Ryniker, K. A., Bush, J. K., Auken, O. V. (2006): Structure of Quercus gambelii communities in the Lincoln National forest New Mexico, USA. - Forest Ecol Manag 233: 69-77.

[42] Sarker, S. K., Rashid, S., Sharmin, M., Haque, M. M., Sonet, S. S., Nur-Un-Nabi, M. (2104): Environmental correlates of vegetation distribution in tropical Juri forest, Bangladesh. - Trop Ecol 55: 177-19.

[43] Shaheen, H., Qureshi, R. A., Shinwari, Z. K. (2011): Structural diversity, vegetation dynamics and anthropogenic impact on lesser Himalayan sub-tropical forests of Bagh District, Kashmir. - Pak J Bot 43: 1861-1866.

[44] Sher, H., Aldosari, A., Ali, A., de Boer, H. J. (2014): Economic benefits of high value medicinal plants to Pakistani communities: an analysis of current practice and potential. J Ethnobiol Ethnomed 10: 2-16.

[45] Sheykholeslami, A., Kia, P., Kia, L. A. (2011): A study of tree distribution in diameter classes in natural forests of Iran (Case Study: Liresara Forest). - Ann Bio Res 2: 283-290.

[46] Shinwari, Z. K., Khan, A. S., Nakaike, T. (2003): Medicinal and Other Useful Plants of District Swat, Pakistan. - Al Aziz Communications, Peshawar, Pakistan.

[47] Siddiqui, M. F., Ahmed, M., Wahab, M., Khan, N. (2009): Phytosociology and structure of Pinus roxburghii Sargent (Chir Pine) in lesser Himalayan and Hindukush range of Pakistan. - Pak J Bot 41: 2357-2369.

[48] Siddiqui, M. F., Ahmed, M., Shaukat, S. S., Khan, N. (2010): Advance multivariate techniques to investigate vegetation-environmental complex of pine forests of moist area of Pakistan. - Pak J Bot 42: 267-293.

[49] Song, M., Zhou, C., Ouyang, H. (2004): Distributions of dominant tree Species on the Tibetan Plateau under current and future climate scenarios. - Mt Res Dev 24: 166-173.

[50] Springers, U., Klee, J. (1954): Prüfung der Leistungsfähigkeit von einigen wichtigeren Verfahren zur Bestimmung des Kohlenstoffs mittels Chromschwefelsäure sowie Vorschlag einer neuen Schnellmethode. - J Plant Nutr Soil Sci 64: 1-26.

[51] Stroke, M. A., Smiley, T. L. (1996): An Introduction to Tree-Ring Dating. - University of Chicago Press, Chicago.

[52] Ter Braak, C. J. F. (1986): Canonical correspondence analysis: a new eigenvector technique for multivariate direct gradient analysis. - Ecology 67: 1167-1179.

[53] Thomas, C. D. (2011): Translocation of species, climate change and the end of trying to recreate past ecological communities. - Trends Ecol Evol 26: 216-219.

[54] Thomas, C. D., Alison Cameron, A., Green, R. E., Bakkenes, M., Linda, J., Beaumont, L. J., Collingham, Y. C., Erasmus, B. F. N. et al. (2004): Extension Risk from Climate change. - Nature 427: 145-148.

[55] Trevidi, M. R., Morecroft, M. D., Berry, P. M., Dawson, T. P. (2008): Potential effects of climate change on plant communities in three montane nature reserves in Scotland, UK. Biol Conserv 141: 1665-1675.

[56] Uprety, Y., Asselin, H., Bergeron, Y., Mazerolle, M. J. (2014): White pine (Pinus strobus L.) regeneration dynamics at the species natural limits of continuous distribution. - New Forest 1-18. 
[57] Wang, S. W., Zhu, J. H., Cai, J. N. (2004): Inter decadal variability of temperature and precipitation in China since 1880. - Adv Atoms Sci 21: 307-313.

[58] Xing, P., Zhang, Q. B., Baker, P. J. (2012): Age and radial growth pattern of four tree species in a subtropical forest of China. - Trees 26: 283-290.

\section{APPENDIX}

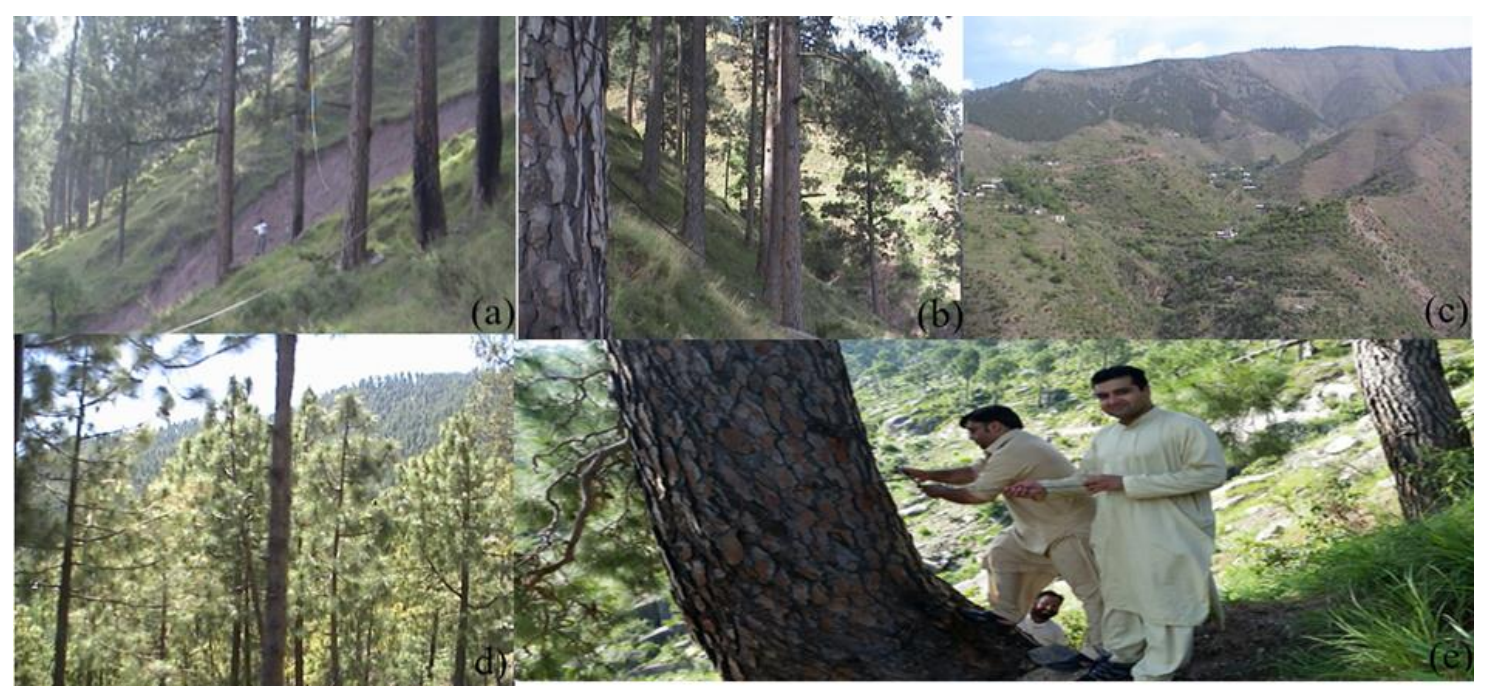

Appendix 1. Examples of ecosystems of a Pinus roxburghii landscape, Swat Hindukush Range Mountains of Pakistan (a) contains trees with obvious fire scars and with dry surface soils lose by landslide (b) young forest stand with poor understorey cover due to overgrazing, (c) private forest conserved by the local residents, (d) successfully regenerating young forest following harvesting or natural disturbance (e) coring a huge diameter tree using an increment borer at Karakar sampling site 